\title{
Las relaciones México-Golfo Pérsico: el fortalecimiento de lazos (2012-2018)
}

\author{
Mexico and Persian Gulf states relations: strengthening links (2012-2018) \\ Alejandra GALINDO \\ Universidad de Monterrey \\ alejandra.galindo@udem.edu \\ https://orcid.org/0000-0003-0135-6802
}

Recibido 17/3/2019. Aceptado 20/5/2021

Para citar este artículo: Alejandra Galindo (2021): "Las relaciones México-Golfo Pérsico: el fortalecimiento de lazos (2012-2018)" en Revista de Estudios Internacionales Mediterráneos, 30, pp. 148-167.

Para acceder a este artículo: https://doi.org/10.15366/reim2021.30.008

\section{Resumen:}

En los últimos dos sexenios del gobierno mexicano, a partir del 2000, México estableció vinculaciones con los países del Medio Oriente, aunque de manera fragmentada. Sin embargo, durante la presidencia de Peña Nieto (2012-2018), el gobierno mexicano fortaleció lo lazos con los países árabes del Golfo Pérsico. El objetivo de este artículo es indagar sobre cómo el gobierno ha usado la diplomacia económica para atraer el interés de los países de la zona, a raíz de la aprobación de las reformas estructurales en México. El analizar cómo fueron los acercamientos, los acuerdos y sus efectos en las relaciones comerciales, nos permitirá evaluar esta nueva fase en las relaciones de México con los países de esa región.

Palabras clave: Política exterior/ diplomacia económica/ México/golfo Pérsico/

\section{Abstract:}

During the last two Mexican government administrations, since the year 2000, Mexico established links with Middle East countries, although not in a cohesive way. In addition, during the presidency of Peña Nieto (2012-2018), the Mexican government also strengthened its relationships with the Persian Gulf's Arab countries. The main purpose of this paper is to analyze how the government used economic diplomacy to attract the interest of these countries, since the approval of Mexican structural reforms. This study will allow us to assess how these approaches were produced, the agreements they led to, and its effects on the commercial relations.

Keywords: Foreign policy/ Economic diplomacy/ Mexico/ Persian ulf/ 


\section{Introducción}

Durante el sexenio presidencial de Peña Nieto (2012-2018), el Medio Oriente se convirtió en un objetivo relevante para el quehacer diplomático como parte del plan para lograr borrar la imagen de México asociada al narcotráfico y consolidar las reformas estructurales logradas al inicio del mandato presidencial a través de la atracción de inversiones, cooperación e intercambios con el país. Tanto el plan de desarrollo como el plan sectorial elaborados por la Secretaría de Relaciones Exteriores (SRE) enfatizaron dicho objetivo.

En el plan de desarrollo (2013-2018), se puede notar cómo el enfoque de la política exterior de México planteó una presencia más activa en el escenario internacional y continuó enfatizando los aspectos económicos y comerciales. En este sentido, la promoción de México para atraer inversiones, turismo y comercio ocupó un lugar central en la estrategia.

"Un México con Responsabilidad Global buscará ampliar y fortalecer la presencia del país en el mundo; reafirmar el compromiso de México con el libre comercio, la movilidad de capitales y la integración productiva; promover el valor de la nación en el mundo mediante la difusión económica, turística y cultural, y velar por los intereses de los mexicanos en el extranjero" (Plan Nacional de Desarrollo 2013-2018).

En el plan sectorial de la Secretaría de Relaciones Exteriores (SRE) se establecieron como principales prioridades: el "contribuir a "la prosperidad" a través de la promoción de México como destino para atraer capital y como plataforma de acceso a otros mercados; la promoción del desarrollo incluyente y sostenible, el fortalecimiento del Estado de derecho, la paz y la seguridad. A partir de estas prioridades se plantearon 5 objetivos: impulsar las relaciones bilaterales, contribuir a los foros multilaterales, impulsar una política de cooperación para el desarrollo, promover a México y proteger los intereses y derechos de los mexicanos en el extranjero.

Todo gobierno señala estar comprometido en la búsqueda del desarrollo y bienestar de su país, pero el modo en que lo realiza y su relación con la política doméstica es determinante para su logro. Los objetivos y prioridades del Plan Nacional de Desarrollo y del plan sectorial de la Secretaría de Relaciones Exteriores buscaron objetivos principalmente económicos, donde la región del Golfo Pérsico se resaltó como uno de los escenarios principales para el fortalecimiento de relaciones e intercambio. La política implementada por el gobierno mexicano en el sexenio de Peña Nieto fue una diplomacia activa, emulando el tipo de política exterior que se había venido desarrollando desde los años noventa, aunque entonces mayoritariamente enfocada a Estados Unidos y Europa.

De acuerdo con Okano-Heijmans, la diplomacia económica implica "el uso de medios políticos para influenciar las negociaciones internacionales con el objetivo de reforzar la prosperidad económica y el uso de la influencia económica para incrementar la estabilidad política de una nación" (2013: 29-30). Este tipo de diplomacia comprende a la diplomacia comercial, la cual busca la promoción de los intercambios de bienes y servicios, la diplomacia de las negociaciones comerciales (trade diplomacy) y la diplomacia financiera encargada de las políticas monetarias y financieras. El Estado se complementa con la red de actores nacionales (dependencias gubernamentales, empresas, organismos no gubernamentales), aunque sigue siendo el principal actor. El quehacer de la diplomacia económica toma en cuenta el contexto, los escenarios en los que se realiza, los actores y el proceso en sí donde se articulan una serie de políticas encaminadas al logro de los objetivos planteados, pues las acciones o instrumentos utilizados impactan tanto en el ámbito económico y político, al mismo tiempo que éstos se encuentran interconectados (Okano-Heijmans 2013: 30-32). 
Esta contribución es el producto de varias estancias de investigación en Arabia Saudita $(2008,2010)$ Emiratos Árabes (2017) y Qatar (2017), en las cuales se realizaron entrevistas a funcionarios, empresarios locales y mexicanos en la región, además de entrevistas realizadas en la ciudad de México con la finalidad de conocer a algunos de los actores involucrados y cómo era el proceso de formulación e implementación de las políticas hacia la región del Golfo. Este material se complementa con el uso de fuentes periodísticas con la finalidad de recabar información sobre las acciones concretas del gobierno mexicano, una vez que se identificaron sus políticas y acciones generales, además de obtener información sobre inversiones realizadas, pues por lo general esta información no se encuentra centralizada y es difícil su acceso.

El propósito de este artículo es examinar cómo la diplomacia económica mostró una línea de continuidad con la orientación de apertura comercial seguida por gobiernos anteriores, pero marcó una diferencia importante al lograr la firma de acuerdos jurídicos y comerciales esenciales para impulsar la inversión y la promoción de exportaciones con algunos países árabes de la región del Golfo Pérsico. Si bien a primera vista pareciera que esta política dio resultados positivos con el logro de acuerdos e intercambios comerciales, la estrategia de activación de lazos se fue realizando sobre la marcha y sin una adecuada articulación de los actores involucrados y con políticas de alcance limitado, desaprovechando las acciones realizadas de forma efectiva y sin una perspectiva a largo plazo que permita consolidar el acercamiento con esta región.

Con la finalidad de enmarcar los cambios en la política exterior hacia Medio Oriente y la región del Golfo Pérsico durante el sexenio de Peña Nieto, la primera parte del artículo presentará un análisis de los hitos relevantes que caracterizaron la dinámica interregional. La segunda parte analizará los acercamientos hacia los países árabes del Golfo Pérsico en el periodo comprendido entre 2012 y 2018 mediante el estudio de las estrategias político-económicas delineadas para lograr elevar el volumen de comercio e inversiones a través de la diplomacia económica. Finalmente se hará una reflexión sobre las ventajas y desventajas de la diplomacia económica mexicana a la luz de este estudio de caso.

\section{Una diplomacia poco activa}

La política exterior de los gobiernos mexicanos hacia la región del Golfo Pérsico ha sido pasiva y reactiva desde el siglo pasado hasta los primeros años del nuevo milenio. La región se mantuvo fuera de la atención de las diferentes administraciones por diversas razones. Podemos señalar que en su inicio el gobierno posrevolucionario (1930-1960) estuvo forjando su autonomía y sobre todo sus relaciones exteriores con su principal vecino del norte, Estados Unidos, como medida para dar estabilidad y viabilidad al México independiente. Las relaciones con el Medio Oriente se canalizaron a través de las representaciones diplomáticas de Egipto y Líbano, en el siglo XIX y hacia la primera mitad del siglo XX (Varela y Sánchez, 2011). Posteriormente, las relaciones se acrecentaron debido al activismo del presidente Luis Echeverría (1970-1976) y su política orientada a los países del Tercer Mundo, como estrategia para ganar legitimidad interna y promover tanto la Carta de Derechos y Deberes Económicos como su candidatura para ser Secretario General de Naciones Unidas. Con tales objetivos, Echeverría fue un presidente que aprovechó el plano exterior para enfrentar los problemas domésticos y como contrapeso a las políticas del gobierno norteamericano (Brun y Garza, 2019: 18-20). Su viaje presidencial por los países del Medio Oriente y Norte de África en 1975, lo convirtió en el primer presidente mexicano que realizó una gira a la zona, visitando Argelia, Arabia Saudita, Egipto, Irán, Israel, Jordania y Kuwait.

Producto de estos viajes fue el establecimiento de relaciones diplomáticas con los países de la región. Bajo la administración de Echeverría se otorgó el reconocimiento a la Organización para la Liberación de Palestina (OLP). Cabe resaltar que las representaciones de algunos de estos países habían mostrado interés por establecer relaciones diplomáticas con México desde años atrás. Un ejemplo, es el caso de Arabia Saudita, país que desde 1952 había solicitado el establecimiento de relaciones con México, pero éste sólo se llevó a cabo ocho años después. Además, la apertura de la 
embajada mexicana en Riad tuvo que esperar hasta $1980^{1}$. Otro caso es el de Irán, cuyo gobierno también lo intentó en tres ocasiones $(1937,1956$ y 1963), hasta que finalmente con la visita del presidente Echeverría se realizó la apertura de embajadas (Galindo, 2011). Echeverría aprovechó el interés de estos países y pudo vislumbrar áreas de cooperación, sobre todo en materia de hidrocarburos y material de infraestructura para la industria petrolera de estos países. En general esta falta de reciprocidad fue producto de varias causas de acuerdo con la temporalidad marcada por el proceso de transformación del país y su proyecto de modernización. Sin embargo, dos causas recurrentes para explicar la debilidad de las relaciones han sido la falta de presupuesto para cubrir la apertura de embajadas y la "natural" concentración de la agenda de política exterior en la relación bilateral México-Estados Unidos, agenda que también ha "condicionado" la percepción de los tomadores de decisiones y el tipo de políticas hacia la región del Medio Oriente en general.

La política posterior fue muy poco activa, debido a que la atención se dirigió más hacia los problemas domésticos derivados de la crisis de la deuda externa y el proceso de liberalización económica que culminó con la firma del Tratado de Libre Comercio de América del Norte (TLCAN) en 1994. El acercamiento hacia la región se dio en términos del involucramiento de México en la política multilateral.

A partir del gobierno de Vicente Fox (2000-2006), de alternancia con el Partido Acción Nacional (PAN) en el poder, la política de México hacia el Golfo Pérsico árabe fue un tanto accidentada. Los acontecimientos del 11 de septiembre de 2001, la cercanía con Estados Unidos y la necesidad de México para reintegrarse con un papel más activo en el ámbito internacional produjeron un impasse con la región y retrasaron las políticas que hubieran permitido una relación más cercana. La lectura de los tomadores de decisiones, presidente y Secretarías de Economía y Comercio, que desde el Tratado de Libre Comercio se alejó más de la cancillería y se concentró en Norteamérica, no logró articular una política exterior coherente y asertiva. Por un lado, México y Chile defendieron la negativa a una invasión a Irak en 2003 y se mostraron a favor de las negociaciones en 2002. Por el otro, México cerró su embajada en Arabia Saudita, el principal interlocutor con los países del Golfo Pérsico y principal exportador de petróleo, argumentando la reducción de presupuesto ${ }^{2}$. Esta oficina se reabrió en 2003, lo que al final implicó más gasto que ahorro. Además, el gobierno mexicano no evaluó la necesidad de abrir una oficina comercial en la zona, como lo habían sugerido desde finales de los noventa diplomáticos mexicanos operando desde el terreno, quienes señalaron la importancia de la actividad comercial y financiera que tenían los países de la región y en especial los Emiratos Árabes Unidos (EAU).

\footnotetext{
${ }^{1}$ Con la caída del Sha de Irán en 1979, la embajada mexicana cerró y en 1980, el gobierno mexicano abrió la embajada mexicana en Arabia Saudita. Hasta ese momento las relaciones con este país eran gestionadas desde la embajada en EI Líbano.

${ }^{2}$ Durante este tiempo se cerraron las embajadas de Noruega, la representación de México ante la OCDE. La postura oficial ante esto fue la reducción presupuestal del 20\%. Véase García Ariadna ( 2002). “Prevé SRE cerrar más embajadas por recorte", El Universal, 18 de diciembre, disponible https://archivo.eluniversal.com.mx/nacion/91796.html [consulta: 19 de marzo 2019]
} 


\section{La reactivación de los lazos}

Durante la presidencia de Felipe Calderón (2006-2012), el Medio Oriente, en particular los países del Consejo de Cooperación para los Estados Árabes del Golfo (CCEAG) son enunciados como parte de los objetivos de la política exterior. La inclusión en el plan de Desarrollo Nacional significa que la zona se convierte en un área en la cual México debe proyectar la cooperación y sus intereses económicos. Además, establece específicamente que se debe fortalecer el intercambio dentro del Fondo de Cooperación Liga Árabe-México y con los países del CCEAG (Plan Nacional de Desarrollo 2006-2012: 305).

La zona durante este periodo cobró importancia para México desde el punto de vista comercial y financiero y también en el ámbito multilateral durante la preparación de la cumbre de las Naciones Unidas sobre Cambio Climático (COP16) celebrada en México en 2010. En efecto, la entonces subsecretaría de Relaciones Exteriores, Lourdes Aranda, visitó Emiratos Unidos y Qatar en 2007, y posteriormente viajó a Arabia Saudita, Kuwait y EAU. Gracias a estas visitas, la subsecretaria pudo dialogar con autoridades de los fondos soberanos, cámaras de comercio y preparar el camino para que eventualmente se abrieran embajadas en los EAU y Qatar. En ambos casos fueron las primeras visitas de un funcionario mexicano de alto nivel a estos países, después de las realizadas por Echeverría en los setenta, con excepción de Qatar que no había recibido al Jefe de Estado. Como consecuencia de estos encuentros diplomáticos se abrieron las embajadas de México en Kuwait en 2011 y en EAU en 2012 y la de este país en México dos años antes. De igual modo se estableció el mecanismo de consultas bilaterales con Arabia Saudita en 2011.

En el ámbito comercial, México abrió la oficina de promoción de comercio ProMéxico en Dubái en 2007, junto con un consulado. Esta representación permaneció hasta 2012, cuando se abrió la embajada mexicana en Abu Dabi. El objetivo en un principio era atraer inversiones a México y promover el comercio bilateral, ayudando a empresas mexicanas a exportar a los países de la región. Los objetivos planteados no fueron del todo cubiertos, debido al personal limitado del Consulado y de ProMéxico para tratar distintos temas con los países de la región. Estos pasos no resultaron en un acercamiento bilateral significativo, ya que desde la apertura del Consulado solamente habían entrado en vigor dos acuerdos: la supresión de visas para pasaportes diplomáticos, oficiales y de servicios y el acuerdo para evitar la doble imposición y prevenir la evasión fiscal en materia de impuestos sobre la renta. El logro de ProMéxico fue la movilización de inversión mexicana hacia los EAU en la bolsa Nasdaq. Ese fue el enfoque de la Oficina; la promoción comercial era realizada por las embajadas. Con la apertura de la Oficina y el Consulado se lograron visitas en promedio de 10 a 15 empresas por año entre el 2007 al 2012, las cuales también aprovechaban para viajar a otros países de la zona.

Como complemento de estos esfuerzos debe subrayarse el aporte de las misiones comerciales a varios países de África y el Medio Oriente, realizadas en gran parte bajo el auspicio de la Cámara de Comercio Árabe Mexicana. A Arabia Saudita (de 2007 a 2011); Emiratos Árabes Unidos (2006 a 2011); Kuwait (2007, 2008, 2010 y 2011); Qatar (2011) (Sexto informe de Relaciones Exteriores, 2012: 83).

\section{Recuperando el tiempo perdido}

La administración de Peña Nieto (2012-2018) dio continuidad a la reactivación de lazos entre México y los países del CCEAG, a diferencia de administraciones pasadas, pero manteniendo el enfoque económico de la política exterior. La razón que explica esta continuidad, como se mencionó anteriormente, es que el gobierno mexicano apostó por las grandes reformas estructurales, por lo que había que atraer inversión al país para implementarlas.

Once reformas se aprobaron, una de las más importantes y que desató una fuerte crítica fue en el sector energético, pues el petróleo es una importante fuente de riqueza para México y ha sido 
considerado un símbolo de la soberanía del país ${ }^{3}$. La reforma logró la apertura a la inversión privada y extranjera para la exploración y explotación de hidrocarburos, al mismo tiempo que se abrió el sector de la electricidad a la participación de empresas privadas nacionales y extranjeras. Las otras reformas se dieron en el terreno de las telecomunicaciones, laboral, hacendaria, educativa, electoral y constitucional. Más allá de las críticas hechas a las reformas y el proceso para su realización, el logro de éstas presentaba a México en el exterior como una economía moderna y con una gran capacidad de crecimiento ${ }^{4}$, en oposición a la imagen de un país violento y en guerra contra el narcotráfico prevaleciente durante el sexenio presidencial anterior ${ }^{5}$.

En lo que se refiere al Medio Oriente, el gobierno estableció como línea principal de acción ampliar la presencia de México para la promoción del intercambio, político, comercial y cultural. Las estrategias consideradas consistieron en el aumento de la presencia de México en la zona, fomentando la cooperación en temas como energía, seguridad alimentaria y cuestiones de seguridad. A nivel multilateral se fomentó la concertación en temas globales como la seguridad, la prevención de conflictos y el desarme. Otra cuestión relevante fue que el Plan Nacional de Desarrollo señalaba específicamente la importancia de impulsar inversiones mutuamente beneficiosas, aprovechando los fondos soberanos de los países árabes del Golfo Pérsico, así como también establecía como objetivo el aumento en el número de turistas de esta zona a México (Plan Nacional de Desarrollo 2013-2018: 148-149).

Sumado al interés de México sobre el Golfo Pérsico, la crisis económica internacional del 2008-2009, aceleró cambios en los patrones de comercio y diversificación de las inversiones de los Fondos Soberanos de los países de la región y la provisión de productos alimentarios. En general debido a las restricciones de los mercados de Estados Unidos y de Europa, la tendencia a incrementar el intercambio con economías emergentes creció especialmente hacia Asia y también hacia América Latina ${ }^{6}$. Otro factor importante que contribuyó a aumentar el interés fue la cuestión de la seguridad alimentaria, pues los países del Golfo $^{7}$, pese a esfuerzos por incrementar la producción doméstica

\footnotetext{
${ }^{3}$ Sobre esta reforma en particular véase Wood, Duncan ed. (2018): La nueva reforma energética de México, Washington, Mexico institute, Woodrow Center, disponible en
} https://www.wilsoncenter.org/sites/default/files/media/documents/publication/la nueva reforma energetica de mexico.pdf [consulta: 20 de marzo 2019].

${ }^{4}$ Como se señala la llegada de Peña Nieto al gobierno, su intenso despliegue de entrevistas y promoción del exitoso futuro de México con las reformas cambiaron la narrativa de los medios de comunicación internacionales sobre el país, pero poco se aprovechó el famoso "momento mexicano" ante el deterioro del acuerdo de los partidos con la reforma del petróleo. Pellicer, Olga (2014): "La política exterior de México bajo un nuevo presidente", Anuario Cidob

https://www.cidob.org/articulos/anuario_internacional_cidob/2014/la_politica_exterior_de_mexico_bajo_un_nuevo presidente [consulta: 20 de marzo 2019].

${ }^{5}$ Las reformas fueron polémicas y para algunos analistas insuficientes. Las más criticadas fueron las de energía, telecomunicaciones y de educación. Las reformas se apoyaron en un discurso de expectativas de crecimiento a corto plazo, pero dadas las variables internacionales y la situación interna, el crecimiento fue menor a lo esperado. Al respecto véase: Navarro, Ma. Fernanda (2018). "EPN: Fin de ciclo | El sexenio perdido en crecimiento económico", Forbes, 30 de agosto 2018, disponible en: https://www.forbes.com.mx/epn-fin-de-ciclo-el-sexenio-perdido-en-crecimientoeconomico/ [consulta: 20 de marzo 2019].

${ }^{6}$ Véase Economist Intelligence Report, (2016). Bridging the Gulf: Latam-GCC trade and investment, disponible en https://eiuperspectives.economist.com/sites/default/files/EIUDubai\%20Chamber\%20Bridging\%20the\%20Gulf\%2027th\%200ctober\%202016.pdf [ consulta: 8 de diciembre 2019]

${ }^{7}$ Estos países exportan entre el $60 \%$ y $90 \%$ de los productos alimentarios. La cuestión de la seguridad alimentaria ha estado en la agenda de estos países desde la década de los setenta cuando Estados Unidos amenazó con cortar el suministro del trigo a los países exportadores de petróleo como medida en contra del embargo petrolero. Sin embargo, esta dependencia se ha ido profundizando a lo largo de los años y los países han adoptado diferentes estrategias con 
de alimentos, la dependencia de la importación de productos alimentarios continuó y se vio afectada por el aumento de los precios y las limitaciones a las importaciones por parte de algunos de sus proveedores.

En términos generales, la política exterior hacia el Medio Oriente en el sexenio de Peña Nieto fue de corte tradicional con relación a las problemáticas de la zona, actuando de acuerdo con las posturas legalistas de la política exterior mexicana, emitiendo comunicados de apoyo genérico a la resolución los conflictos, cooperando en términos de energía, seguridad y desarme. El gobierno mexicano continuó dando su apoyo a palestinos con ayuda económica (1,100 millones de pesos mexicanos) a través de las Naciones Unidas en 2014 para la reconstrucción de Gaza (Oficina de Enlace, 2018), al igual que contribuyó en fondos internacionales para ayudar a refugiados sirios en Líbano, Turquía, Egipto, Jordania e Irak. 1 millón de US dólares a través del Fondo de Naciones Unidas para la Infancia (Unicef) y 2 millones de US dólares al Programa Mundial de Alimentos (PMA) y al Alto Comisionado de las Naciones Unidas para los Refugiados (ACNUR) (El Universal, 2016a). En cuanto a los conflictos regionales condenó el uso de armas químicas por parte de Siria (2013 y 2017) y siguió con la política de desnuclearización de la zona, respaldando el acuerdo logrado con Irán en 2015. Asimismo, el gobierno se acercó a los gobiernos de Turquía y Jordania, con los cuales inició pláticas para el establecimiento de tratados de libre comercio.

Si bien México había logrado restablecer las relaciones con Arabia Saudita después del cierre de la embajada, tuvo que replantear su estrategia frente a los otros países del Consejo de Cooperación del Golfo. Aunque se habían realizado los primeros acercamientos con EAU, Kuwait y Qatar durante el sexenio anterior, faltaba un mayor intercambio de instrumentos jurídicos internacionales para que se incrementará el perfil de comercio e inversiones con la región. De este modo, la estrategia seguida fue concretar dichos acuerdos. Por tal razón al inicio de la nueva administración, funcionarios de la cancillería realizaron viajes a esos países de la región con la finalidad de promover y explorar las oportunidades en los países del Golfo, para luego concretar acuerdos con la visita del presidente Enrique Peña Nieto en enero de 2016 y posteriormente con el Secretario de Agricultura, Ganadería, Desarrollo Rural, Pesca y Alimentación (Sagarpa) para promover la industria agropecuaria.

En 2014, se realizó la primera gira del gobierno de Peña Nieto al Medio Oriente, siendo la región del Golfo Pérsico el destino de este primer viaje diplomático. El entonces Secretario de Relaciones visitó Kuwait, EAU y Arabia Saudita. Este viaje tuvo el propósito de promover México para el intercambio y el comercio. El entonces secretario de Relaciones Exteriores, José Antonio Meade, estuvo acompañado por el Director General del Banco Mexicano de Comercio Exterior (Bancomext), el Director General de Proméxico, el Director de la filial comercializadora de Petróleos Mexicanos (Pemex), Director de Banca e Inversión y Delegado del Fondo Fiduciario de Infraestructura y el Director del área de Evaluación y Cooperación Internacional del Consejo Nacional de Ciencia y Tecnología (Conacyt) (Reporte de Relaciones Exteriores, 2014: 88).

Los resultados de este acercamiento fueron la firma del Memorándum de Entendimiento para consultas entre la secretaría del CCEAG y la Secretaría de Relaciones Exteriores. Cabe destacar que dicho organismo llevaba algunos años sin firmar un documento de esta naturaleza con algún país $u$ organismo, por lo que mostró un voto de confianza a México. Durante esta gira, el canciller promovió las inversiones en México en los sectores de construcción, turismo e industria automotriz, así como el intercambio en materia educativa y tecnológica. Con el gobierno de Kuwait se realizó un convenio para el establecimiento de una Comisión Conjunta para la Cooperación entre los dos países. Además, en su visita a los EAU, se identificaron que las áreas de mayor cooperación bilateral podían ser la energética y turística (Informe de labores, Senado de la República, 2013-2014: 89). En

alcances limitados para enfrentar dicha vulnerabilidad. Al respecto véase: Woertz, Eckart (2015): Oil for Food. Oxford, Oxford University Press 
el caso de Qatar, se anunció la apertura de la embajada mexicana en ese país y de la embajada qatarí en México, que desde la administración pasada se había contemplado.

Después de la visita del canciller, en abril de ese mismo año, importantes empresarios mexicanos visitaron Arabia Saudita y Kuwait, entre ellos Carlos Slim, Carlos Peralta Quintero y Juan Carlos Peralta del Río del grupo IUSA; Olegario Vázquez Raña y Olegario Vázquez Aldir, de Grupo Empresarial Ángeles, empresarios vinculados con la administración de Peña Nieto, pero también a la de anteriores gobiernos. Aunque se especuló sobre la posible inversión de Slim en el sector de petroquímica de Arabia Saudita (Esteves, 2013), oficialmente la idea era explorar estos mercados y formar un consejo de negocios entre México y los países del Golfo. En Kuwait, fueron invitados por el Emir para explorar las posibilidades de invertir en proyectos dentro del plan de desarrollo de ese país (El Universal, 2013).

La vista del Canciller fue seguida por la del Subsecretario de Relaciones Exteriores, Carlos de Icaza, quien también estuvo acompañado por representantes de sectores oficiales, al igual que un grupo de empresarios. El objetivo principal fue darle seguimiento a los acuerdos y convenios alcanzados por el secretario, además de la promoción de las empresas mexicanas en estos países y preparar la visita del presidente Peña Nieto a la región.

Gracias a estos encuentros, Qatar Airways empezó con vuelos de carga a la Ciudad de México en junio de 2014, con una frecuencia de 2 vuelos por semana. Lo mismo pasó con la aerolínea emiratí, Emirates Airlines, quien también comenzó con este tipo de vuelos a la capital mexicana en mayo del mismo año ${ }^{8}$. A nivel diplomático, el vicepresidente de EAU y Primer Ministro y Emir de Dubái, Sheikh Mohammed bin Rashid Al Maktoum, visitó México, acompañado de una delegación empresarial. Durante su estancia se celebró la firma del convenio para la firma del Acuerdo de Promoción y Protección Recíproca de Inversiones ${ }^{9}$. En 2015, el Emir Tamim visitó México, primera vista de un monarca qatarí, dentro de la primera gira realizada por el nuevo mandatario a Latinoamérica, además en el marco de los 40 años de las relaciones bilaterales. De esta visita resultaron 5 acuerdos: servicio aéreo para el establecimiento de vuelos comerciales, un Memorándum de Entendimiento (MoU) entre la Cámara de Comercio del Consejo Empresarial para el Comercio Exterior y la Cámara de Comercio de Qatar y otro entre el Banco Central de Qatar y el Banco Mexicano, además de un acuerdo en cooperación técnica (para promover comercio, minería, energía, agricultura, turismo y educación) y entre las dependencias gubernamentales encargadas de la juventud (Comunicado conjunto, 2015; Al Arabiyya, 2015).

Finalmente, la visita del presidente Enrique Peña Nieto se realizó en enero de $2016^{10}$. Esta gira por la península arábiga comprendió las visitas a Arabia Saudita, Kuwait, EAU y Qatar. El presidente estuvo acompañado por los Secretarios de Economía, de Sagarpa, Energía y de Comunicación y

\footnotetext{
8 Poco a poco las dos aerolíneas han expandido sus vuelos de carga para incluir otras ciudades mexicanas importantes en términos de industria y producción. En el 2019, Emirates inició un vuelo diario a Dubái, con escala en Barcelona.

${ }^{9}$ Este acuerdo fue aprobado por México hasta el 2018, mientras que en Emiratos se aprobó de forma rápida.

${ }^{10}$ Esta visita estuvo programada para un año antes en 2015, pero debido a la desaparición de los estudiantes de Ayotzinapa en septiembre de 2014, los escándalos de la compra de la "Casa Blanca" que llevó a la suspensión de la concesión para el tren de alta velocidad México-Querétaro, donde uno de los inversionistas del gobierno de Peña Nieto estuvo involucrado en dichos sucesos, la gira se tuvo que reprogramar. Al respecto véase, Aristegui Noticias, (2014). "La casa blanca de Enrique Peña Nieto", 9 de noviembre, disponible https://aristeguinoticias.com/0911/mexico/la-casa-blanca-de-enrique-pena-nieto/ [consulta: 19 de marzo 2019]
} 
Transportes y de empresarios mexicanos ${ }^{11}$. La visita de Peña Nieto fue la primera de un mandatario mexicano a EAU y Qatar, y la segunda visita oficial a Kuwait y Arabia Saudita después del presidente Luis Echeverría en 1975. En total se firmaron 43 acuerdos en las ramas de energía, comercio, educación y turismo.

Peña Nieto promocionó las facilidades y apertura de México con las reformas estructurales recién logradas. Como se afirma en un artículo periodístico, la invitación a "participar en proyectos de infraestructura que se están realizando en México y en especial los sectores que se han abierto a la inversión privada, el de las telecomunicaciones y el sector energético" fue reiterativa en los diferentes encuentros que sostuvo el presidente (El Economista, 2016). En cada uno de los países participó en foros de negocios, reuniones con las cámaras de comercio, donde explicó las reformas estructurales y los proyectos de inversión que su gobierno estaba impulsando.

En Arabia Saudita asistió al Foro Internacional de Energía. Entre los 11 acuerdos logrados destacan el de servicios aéreos, el Acuerdo para Evitar la Doble Imposición y Prevenir la Evasión Fiscal en Materia de Impuestos sobre la Renta ${ }^{12}$, el MoU entre Pemex y la empresa petrolera saudita ARAMCO, otro entre Bancomext y el Fondo Saudita para el Desarrollo y entre la Cámara de Comercio del Consejo Empresarial y la Cámara de Comercio Saudita (El Economista, 2016). En EAU, Peña Nieto fue el orador invitado en el evento de la Semana de Sustentabilidad de Abu Dabi. Trece acuerdos se firmaron con este país, entre ellos el Acuerdo para la Promoción y Protección Recíproca de las inversiones ${ }^{13}$; el MoU para mejorar la cooperación en energías limpias y asuntos energéticos relacionados con el cambio climático, otro $\mathrm{MoU}$ entre los ministerios de energía de los países y otro entre Pemex y la Abu Dhabi National Oil Company (ADNOC) y Mubadala (compañía de inversión de uno de los fondos soberanos del país). Otros de los acuerdos correspondieron a las áreas de educación y turismo (Reséndiz, 2016).

Con Kuwait se firmaron alrededor de 9 acuerdos, destacándose el MoU para impulsar el comercio e inversiones entre la Autoridad Kuwaití para la Promoción de Inversiones y Proméxico, otro MoU en materia de cooperación energética fue firmado por los ministros de Comercio e Industria, Finanzas y Petróleo con la Secretaría de Energía. Otros de los acuerdos firmados cubrieron las áreas de salud, educación superior y servicios aéreos (Kuwait Times, 2016). En la visita a Qatar, el presidente logró concretar 10 acuerdos: dos Memoranda de entendimiento: uno en materia energética y otro entre los bancos centrales de los dos países y un acuerdo para proveer a la Copa Mundial de Futbol de Qatar. Además, se concluyeron acuerdos en los ámbitos de educación y cooperación cultural (El Universal, 2016b).

Los acuerdos firmados por Pemex con las tres compañías petroleras buscaron atraer la inversión para la exploración, distribución e infraestructura del petróleo. De acuerdo con el comunicado de prensa de Pemex, el acuerdo con Mubadala fue el más valioso debido a que la compañía emiratí se comprometió a proveer una cooperación en infraestructura por más de 4 mil millones de US dólares. En este documento, se especifica la cooperación en la infraestructura de los sistemas de logística

\footnotetext{
11 Los empresarios que acompañaron al presidente fueron los representantes de las diferentes organizaciones empresariales junto con los directivos de empresas como: Guillermo Vogel, vicepresidente de Tenaris/Tamsa; Juan Ignacio Gallardo Thurlow, presidente del Consejo del Grupo Azucarero de México y del Grupo de Embotelladoras Unidas y Embotelladores Cultiba; el señor Hipólito Gerard Rivero, director general de la Constructora y Edificadora GIA; Alonso Ancira Elizondo, presidente del consejo de Altos Hornos de México; Alfonso Quintana Kawage, presidente del Grupo ICA (empresa de construcción); Daniel Chávez Morán, presidente y fundador del Grupo Hotelero Vidanta; José Chapur Zahoul, presidente y fundador del Grupo Palace Resorts; Fadi Omar Farouk Saboune, director y fundador de Bestground (empresa de alimentos); Juan Alberto Laborin Gómez, Elias Freig, director general de Green Growth Group; Jorge William Karam, CEO del Grupo Hidrosina y Fernando Calvillo Álvarez, director general del Grupo FERMACA (empresa energética). MVS Noticias (2016)." Empresarios acompañan a Peña Nieto al Medio Oriente para participar en reuniones comerciales", 18 de enero, disponible https://mvsnoticias.com/noticias/nacionales/empresarios-acompanan-penanieto-al-medio-oriente-para-participar-en-reuniones-comerciales-394/ [consulta: 8 de diciembre 2020].

${ }^{12}$ Este acuerdo entró en vigor el 26 de enero de 2018

${ }^{13}$ Este acuerdo entró en vigor el 24 de enero de 2018.
} 
del puerto petrolero de Salina Cruz, Oaxaca, el cual requiere de una inversión de más de 3 mil millones de US dólares. También, el acuerdo señala la posibilidad de participar en proyectos elaborados de manera conjunta. Los otros dos acuerdos son más generales y están encaminados a compartir mejores prácticas, tecnología, preparación de recursos humanos, entre otros objetivos (Pemex, 2016).

Con esta gira, tanto el secretario de Sagarpa como el Director General de Bancomext abrieron los ojos a la importancia del sector agropecuario, dado que los países árabes del Golfo dependen de las importaciones para su provisión de productos alimentarios. El representante de Proméxico explicó que desde 2014, este organismo ha buscado la certificación Halal para los productos mexicanos, mientras que la Asociación de Productores de Carne Mexicana ya había identificado este mercado.

Por parte de las empresas, Helvex logró concretar su presencia en la región, mediante el acuerdo para tener un distribuidor exclusivo en la región ${ }^{14}$, a raíz de la vista del presidente. Otra empresa con producción en México, Tenaris Tamsa, logró 160 millones de US dólares para proveer de tubos y conexiones de acero a un proyecto de la Compañía Nacional de Petróleo de Kuwait y otro con ARAMCO por 34 millones de dólares, además de identificar otras oportunidades para vender sus productos (Morales, 2016).

Como se ha podido apreciar, las visitas hechas por el presidente y demás funcionarios del gobierno activaron las relaciones con esta región, permitiendo el intercambio de visitas enfocadas en temas particulares. Dado que este acercamiento es más de tipo económico y comercial, en la siguiente sección examinaremos los intercambios que se han dado y las estrategias seguidas.

\section{Comercio e Inversiones}

De manera general, el comercio de México con estos países ha sido muy bajo, pues las exportaciones se han concentrado en Estados Unidos, Europa y en años actuales se ha observado un crecimiento sustancial con las economías del Pacífico encabezadas por China. Durante los noventa, los socios comerciales relevantes de la zona del Medio Oriente fueron Arabia Saudita e Israel. El tipo de bienes que se han exportado a la región del Golfo Pérsico han sido principalmente productos manufacturados y poco del sector agropecuario, entre ellos principalmente miel y garbanzos.

El despegue del crecimiento de los intercambios con estos países, como se podrá observar en la siguiente tabla, se dio durante la administración del presidente Vicente Fox (2000-2006), acumulando un $37 \%$ de crecimiento promedio anual; mientras que en el periodo de Calderón se redujo a un $15 \%$, periodo en el que incide la crisis mundial de 2008-2009. Con Peña Nieto, el promedio de crecimiento ha estado alrededor del $5.8 \%$. No obstante, a pesar del crecimiento mostrado, el porcentaje que representa es muy bajo; es decir, menos de un punto de las exportaciones totales. Lo anterior nos permite ver en perspectiva el hecho que han sido los mismos empresarios que han destinado sus productos a esta región, sin estar necesariamente bajo una directiva gubernamental.

\footnotetext{
${ }^{14}$ Helvex ya contaba con presencia en este mercado, a través de diferentes distribuidores desde el 2011. El contar con un distribuidor exclusivo traería una mayor venta de sus productos. Para el 2014 , el $5 \%$ de sus exportaciones estaban destinados a los mercados del Medio Oriente. Al respecto véase Bibián, Cinthia (2014). "Helvex abre la llave de Medio Oriente", Expansión, 2 de agosto, disponible http://obrasweb.mx/soluciones/2014/08/04/helvex-abre-la-Ilave-demedio-oriente [consulta: 21 de marzo 2019].
} 
Figura 1 Exportaciones de México a los países del Golfo Pérsico

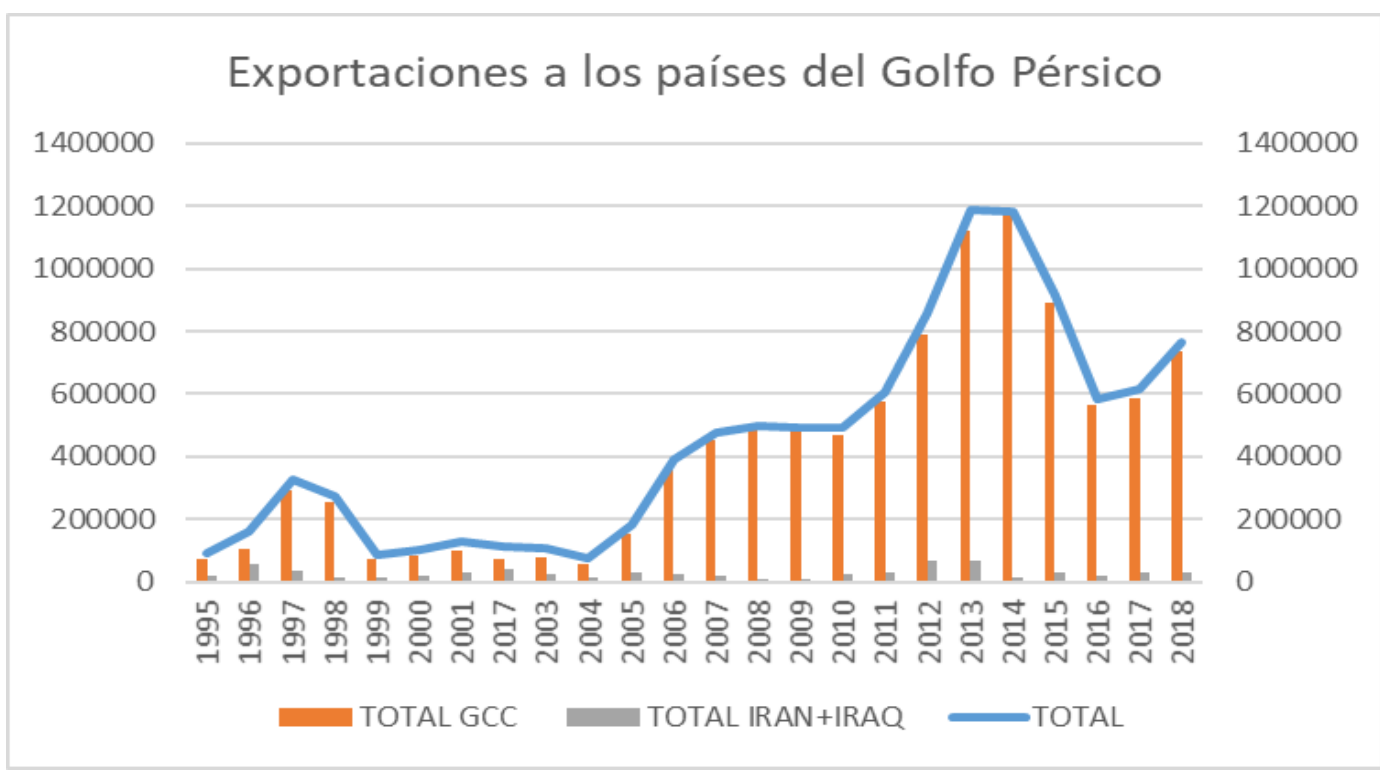

Fuente: elaboración propia a partir los datos estadísticos de la Conferencia de Naciones Unidas para el Comercio y Desarrollo (UNCTAD), disponible en https://unctad.org/statistics

En términos de fomento al comercio e inversiones, la estrategia gubernamental no ha tenido una dirección clara desde tiempos de Calderón. Como se ha expresado, México ha llegado tarde a esta región en comparación con otros países latinoamericanos como Brasil (Galindo, 2018). La apertura de la oficina comercial de Brasil se dio desde 2002, mientras que México la abrió en 2007, pero orientada más a las inversiones que a la promoción de exportaciones. Sin embargo, hay algunas empresas $^{15}$ que por sí mismas se han arriesgado a entrar a este mercado. Cemex, empresa de cemento, con presencia en la región desde 2005 en Dubái y 1999 en Egipto; Kidzania (ciudad de los niños) con franquicias en EAU, Arabia Saudita, Kuwait y Qatar desde 2010; EG corporación dedicada a tubos y bombas desde mediados del nuevo milenio en Arabia Saudita. Además de la exportación de bienes de empresas dedicadas al ramo de la farmacéutica, la industria automotriz y productos alimenticios. Un factor importante que ayudó a mejorar la conectividad interregional fue el inicio de vuelos de cargas por Emirates y Qatar Airways, como se mencionó anteriormente, pues los países de Sudamérica contaban con vuelos de carga y comerciales desde mediados de la primera década del nuevo milenio.

La apertura de la oficina de Proméxico en Qatar en 2015 se hizo con la idea de tener un primer acercamiento con la región, para luego planear una estrategia. En comparación con otras áreas como Europa o América Latina donde se cuenta con una larga experiencia, el área de Medio Oriente requiere de un trabajo coordinado con las demás dependencias gubernamentales (Secretaría de Relaciones Exteriores, Bancomext, Secretaría de Turismo, etcétera), pues son mercados nuevos.

La oficina de Proméxico en Qatar desde 2015 estaba a cargo del área del Levante y el Golfo Pérsico hasta que se abrió la oficina de representación en Dubái en 2016, más la oficina en Marruecos desde 2014 para el norte de África. Hacia la segunda mitad de 2016 hubo un reacomodo de los países cubiertos por cada una de las oficinas. La oficina de Qatar se encargó de trece países, incluidas las

\footnotetext{
${ }^{15}$ En términos generales es necesario señalar que las empresas tienden a exportar sus productos a mercados conocidos y cercanos geográficamente, para México serían principalmente los mercados de Estados Unidos o Latinoamérica. Dependiendo de factores como tamaño de empresa, apoyo institucional, tecnología, entre otros factores, las empresas se arriesgan a mercados no tradicionales.
} 
repúblicas de Asia Central, el Líbano, Jordania, Siria, Sudan y Egipto, mientras que la oficina de Dubái se ocupó de Arabia Saudita, Bahréin, Omán y Yemen.

Para 2016, la representación de Proméxico en Doha contaba con un mapeo de las facilidades y obstáculos para la exportación de los productos en los países de la región, así como también un acercamiento importante con sus principales actores económicos. Además, se estaba trabajando con una empresa emiratí-mexicana para que apoyara a otras empresas en su comercio con EAU desde la zona libre de Jebel Ali, encargándose de la gestión, promoción y distribución exclusiva. En 2016 esta empresa estaba promoviendo 35 productos, todos ellos procesados y del sector alimentario como se pudo constatar durante la visita a la empresa ${ }^{16}$.

Sin embargo, aunque las oficinas de promoción comercial estaban coordinadas con las embajadas respectivas, era una persona responsable de la representación en cada una de las dos, por lo que era difícil cubrir todos los países y oportunidades. Además, dentro de las embajadas, son los propios embajadores o encargados de negocios los que llevan estos asuntos, sin que necesariamente sean personas especializadas en los aspectos económicos o comerciales de estos mercados, ni siquiera especialistas en la zona.

En el caso de la gira realizada por el Secretario de Sagarpa a los países del Golfo Pérsico en mayo de 2016, era evidente como para los colaboradores del Secretario era una novedad el tema de la seguridad alimentaria de los países de la región y la necesidad de diversificar sus importaciones. Participaron 36 empresas, incluyendo representantes de algunos sectores productivos, mediante una convocatoria abierta por parte de la Secretaría ${ }^{17}$. El secretario expuso en Dubái que el gobierno mexicano tenía como objetivo aumentar sus exportaciones agropecuarias de 46 a 1,000 millones de US dólares a los países de la región (Pérez, 2016). Al final de esta gira, las empresas consolidadas como Su-Karne, Grupo Gusi y la Costeña, entre otras, avanzaron en negociaciones de contratos. De acuerdo con un comunicado oficial de la secretaría, en Kuwait, se realizó un acuerdo con un proveedor local y productores mexicanos por 500 millones de pesos (Sagarpa, 2016). La costeña, por su parte, obtuvo la distribución exclusiva de sus productos en Dubái', como se mencionó anteriormente.

La Secretaria de Economía, en conjunto con la Sagarpa, Relaciones Exteriores y Proméxico entre otras dependencias gubernamentales, iniciaron un plan de certificación Halal para los productores mexicanos en 2016 con el objetivo de ampliar las exportaciones de este este sector a la región. El plan consistió en 5 etapas: 1-diagnóstico y oportunidades potenciales, 2-realización de estudios para la definición de productos / mercados objetivo y procesos de certificación particulares, 3-campaña informativa sectorial sobre oportunidades / capacitación y apoyos para certificación y 4-promoción de empresas certificadas en mercados objetivo y 5 -cierre de negociaciones y exportaciones a mercados Halal (Secretaría de Economía, 2016).

Diez empresas ${ }^{18}$ fueron las primeras en recibir la certificación Halal, contando con el subsidio del $50 \%$ del costo del proceso del gobierno. Según fuentes oficiales, para 2017, se esperaba que 100 empresas fueran certificadas. El gobierno promovió la certificación con visitas a empresas y pláticas

\footnotetext{
${ }^{16}$ La empresa mexicana se formó desde 2003 y la asociación con la empresa emiratí se realizó en 2015.

${ }^{17}$ El desconocimiento sobre la cultura de estos países era notorio, pues como comentó uno de los participantes algunos de estos empresarios eran hijos de los dueños de las empresas que tomaban la gira más como vacaciones que como oportunidad de negocios.

18 Grupo Mar; Descafeinadores Mexicanos; Especias Terana-Rus Internacional; Bachoco, Proboca, Buenaventura; Procesados Nestlé, Salsas el Yucateco; así como la reafirmación de los grupos cárnicos Gusi y SuKarne.
} 
sobre este tipo de certificación. Sin embargo, para diciembre de ese año había solamente 50 empresas certificadas (Instituto Halal, 2017), pese a que Sagarpa en julio del mismo año abrió la Consejería Agropecuaria para Medio Oriente en Dubái, la meta no fue cumplida. Factores como el desconocimiento hacia la región y la tendencia natural de las empresas a concentrarse en los mercados geográficamente próximos contribuyen a esta baja participación. Bajo este panorama, se puede señalar que lo que ha prevalecido es la consolidación de empresas grandes y no ha permeado hacia las empresas medianas que puedan también participar en este mercado. Otra cuestión a resaltar es que la exportación de carne, como sucede con otros productos está concentrada fuertemente en el mercado de EEUU, la adquisición de estos certificados abre mercados no solo para países del Medio Oriente, sino también para otros mercados en Asia con población musulmana, por ejemplo, Indonesia, Malasia.

La empresa de Carne Gusi logró un contrato de exportación de 200 toneladas de carne a Qatar. La primera exportación de 20 toneladas se realizó en abril y las demás se hicieron lo largo del año (Gusi, 2017). También en 2017, EAU y el gobierno mexicano firmaron un acuerdo para la exportación de carne halal a este país. En el transcurso del mismo año, autoridades sanitarias emiratís, sauditas y qataris inspeccionaron las plantas de producción de carne bovina y de ave en México (Senasica, 2017). La exportación de carne a los Emiratos Árabes y Arabia Saudita se inició en 2018.

La asistencia a ferias y encuentros en foros regionales también se activó entre 2012 y 2018. En la feria de alimentos de Dubái, Gulfood, 15 empresas mexicanas, apoyadas por Proméxico, participaron por primera vez en 2016; en 2017 fueron 12 empresas y 16 más asistieron en misión comercial o como asistentes (El Correo del Golfo, 2017). Para el año siguiente, 18 empresas participaron, incursionando las empresas de carne, una vez que obtuvieron la certificación halal del gobierno emiratí (El Correo del Golfo, 2018). Otra feria importante en este sector es la celebrada en Jedda, Arabia Saudita, Foodex, donde también se ha contado con la participación de empresas mexicanas, especialmente desde 2014, cuando México contó con un pabellón apoyado por Sagarpa, con la presencia de nueve empresas. También funcionarios de gobierno y directores de empresas han participado en las reuniones del Global Forum Latin America que se celebra en Dubái desde 2017.

Figura 2. Exportaciones a los países visitados del Golfo Pérsico (en US dólares) (1995-2018)

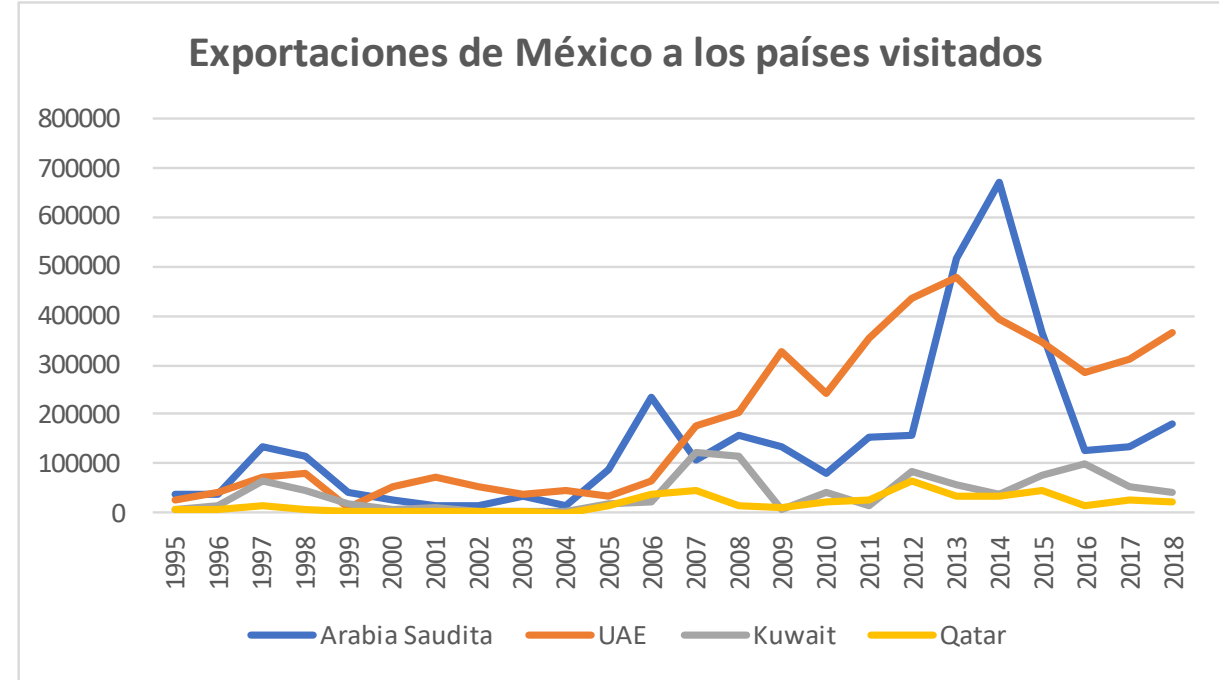

Fuente: elaboración propia a partir de datos estadísticos de UNCTAD, disponible en https://unctad.org/statistics

Las exportaciones han mostrado cierto crecimiento, especialmente con EAU y Qatar. En cambio, con Arabia Saudita, después de un corto crecimiento, se experimentó una baja, que vuelve a recuperarse en 2016. Aunque es relativamente corto el tiempo para apreciar el efecto en el aumento de comercio interregional, la situación con la difícil renegociación del TLCAN, generó inquietud en 
productores del sector agropecuario e influenció que consideraran este mercado como una posibilidad para su diversificación.

En el rubro de las inversiones, los sectores que más interés han despertado han sido el de la energía, el turístico y el de productos agroindustriales. En cuanto a la energía, además de los acuerdos previamente mencionados entre Pemex y las compañías petroleras de Arabia Saudita y EAU, la licitación de exploración de petróleo en el Golfo de México en enero de 2018 concedió a la compañía Nacional de Petróleo Qatarí 5 bloques, 4 en conjunto por la empresa Shell y el otro con la compañía italiana ENI. Esta licitación logró adjudicar 20 bloques de un total de 29, lo cual representa una inversión de 93 mil millones de US dólares (Weber, 2018). Al finalizar ese año Qatar nuevamente adquiere adquirió 35 \% de la explotación del petróleo de la empresa ENI para explorar otros campos petroleros en el área del Golfo de México (El Economista, 17 de diciembre, 2018).

En cuanto al sector de la energía renovable, la empresa Abdul Latif Jameel Energy de Arabia Saudita logró que se le otorgara permiso para invertir en la construcción de una planta solar en México (Habboush, 2018). Asimismo, los fondos de inversión del Grupo Abraaj, también de EAU, planean invertir en México alrededor de 450 millones de pesos en diversos sectores (Rodríguez y Nava, 2017). La construcción de una planta de energía en Chihuahua contó con la participación de este grupo, en asociación con la Comisión Federal de Electricidad y el consorcio American Energy, quienes invertirán 100 millones de US dólares.

En el sector de turismo, el grupo Hakkasan de EAU anunció su asociación con el grupo Mexicano Vidanta para invertir 150 millones de pesos en los hoteles de México. La inversión fue producto de la gira presidencia, donde el CEO del grupo mexicano concretó el negocio con la agrupación de los Emiratos (Prnewswire, 2016).

Con Kuwait, aunque de manera indirecta, el fondo soberano invirtió 550 millones de US dólares en la filial internacional de Gas Fenosa, la cual busca expandir su capacidad en América Latina, incluyendo México (El País, 2015).

Del lado mexicano, pero en el sector de infraestructura, la firma española de construcción FCC, donde Carlos Slim es el mayor accionista, tiene la construcción de líneas de metro en Riad y Doha, en esta última completada en 2019. Otra inversión importante por parte de una empresa mexicana es la de Cinépolis en el rubro de la industria del entretenimiento, quienes se asociaron con grupo locales para abrir salas de cine en los países de la región como Omán, Bahréin, EUA y Arabia Saudita (Anderson, 2019).

\section{Conclusiones}

Como se ha expuesto, la política exterior mexicana hacia los países árabes del Golfo Pérsico ha dado un giro significativo durante el sexenio de Peña Nieto (2012-2018), permitiendo la activación de los intercambios. Para la diplomacia económica un factor importante son los contextos; en nuestro caso, pudimos observar cómo éstos influyeron para aumentar el acercamiento y el intercambio interregional. A partir de la crisis económica de 2008, los países del Golfo intensificaron sus políticas para diversificar los fondos de inversiones e importaciones de productos alimentarios. En cuanto a México, aunque las autoridades tardaron en dirigir su atención hacia la zona, las acciones de acercamiento realizadas desde el sexenio de Felipe Calderón tomaron un nuevo ritmo bajo la administración de Peña Nieto. Sin embargo, continuaron manteniendo el acento en las cuestiones económicas y comerciales trazado desde los noventa. En este sentido, el logro de la administración de Peña Nieto fue la creación del intercambio de bases jurídicas para activar los lazos. Sin embargo, 
la implementación de dichos acuerdos tuvo que esperar por la lentitud del sistema del congreso mexicano, pues los acuerdos firmados en 2016 entraron en vigor recién en 2018.

En términos de estrategia, cuando se empezó con el acercamiento interregional, desde México no se tenía un plan completo que identificara a los actores para lograr los objetivos, ni el cómo hacerlo, independientemente que las labores estaban distribuidas de manera dispersa y poco efectiva, principalmente entre la Secretaría de Relaciones Internacionales, Proméxico, Secretaría de Economía y Sagarpa. Las acciones del gobierno involucraron varias dependencias y la participación de empresarios, en su mayoría ligados a la administración.

En cuanto a la organización de una estrategia integral, los actores oficiales carecían de un liderazgo que diera seguimiento a los esfuerzos de las dependencias gubernamentales. Aunque en términos oficiales la coordinación recaía en funcionarios de la presidencia, en la práctica cada dependencia seguía sus propias acciones. Bajo tal perspectiva, la toma de decisiones estaba en la presidencia y la Secretaría de Relaciones Exteriores (SRE) era un actor más dentro de las acciones realizadas. Nuevamente vemos una continuidad en la toma de decisiones con respecto a la política exterior de México, en donde la SRE no ocupa un lugar central para el diseño y ejecución de acciones, relegando el conocimiento y experiencia del personal diplomático. Del mismo modo que no se establecieron foros o canales de comunicación con aquellas empresas que tenían presencia en la región, para aprovechar su experiencia y conocimiento.

La falta de una estrategia bien definida y el desconocimiento sobre la región fue notoria en términos de cómo se realizó el plan de ProMéxico que, en un inició, abrió la oficina en Doha para explorar las oportunidades y conforme transcurrió el tiempo se fue adaptando. Si a lo anterior sumamos el escaso número de personal para atender los países vinculados a la oficina y que el embajador de Qatar era un embajador designado, sin experiencia en el Medio Oriente, la capacidad de acción fue limitada. Proméxico ya había pasado por una situación similar en el sexenio anterior con la oficina en Dubái. Asimismo, la inexperiencia y falta de conocimiento especializado estaba presente en la Sagarpa, cuyos funcionarios no tenían conocimiento sobre la región y notaban con asombro las políticas de los países en materia de seguridad alimentaria, tema que, no obstante, ha estado en la agenda de la región desde inicios del nuevo milenio.

En cuanto a la industria agropecuaria, aunque ya había algunos productos colocados en los mercados de los países árabes del Golfo Pérsico, el gobierno emprendió una campaña para que empresas mexicanas se certificaran en la producción de alimentos halal, después de la gira presidencial. También la necesidad de este tipo de certificación ya había sido señalada por personal diplomático desde años anteriores, pero nunca había existido una política oficial que proporcionara los mecanismos necesarios para lograr dicha certificación. Solamente aquellas firmas grandes y con experiencia en regiones de Asia contaban con la certificación, entre ellas Sukarne, que desde 2015 la había conseguido de forma independiente y había comenzado a exportar a Egipto. Las exportaciones de carne hacia la región comenzaron en 2017 y para 2019, Qatar, Arabia Saudita y EAU continuaban solicitando la compra de estos productos. Si bien las exportaciones de productos cárnicos se concentran especialmente en Estados Unidos y algunos países de Asia como China y Japón, el inicio de la exportación a esta región puede diversificar las exportaciones a otros mercados con población musulmana y, de este modo, contribuir al mantenimiento del incremento de la producción nacional que se ha observado en los últimos cinco años.

Como pudimos notar, los empresarios que acompañaron a los funcionarios de gobierno fueron de grandes empresas vinculadas con la administración del presidente Peña Nieto, algunas de las cuales lograron importantes acuerdos para inversión y compra de productos mexicanos. En este sentido, son las grandes empresas las que están penetrando en este nuevo mercado y mientras las compañías medianas que pudieron aprovechar este nuevo contexto, no contaron con apoyo oficial. Lo anterior representa una contradicción, pues una de las políticas del sexenio en materia de industria era el apoyo a las empresas medianas para activar y diversificar la base productiva del país. 
La diplomacia mexicana obtuvo aciertos importantes como las inversiones de Qatar en exploración del petróleo, al igual que EUA y Arabia Saudita en el sector de energía renovable. Sin embargo, con una estrategia mejor elaborada e incluyente, donde participaran empresas independientes con experiencia en la región, personal diplomático especializado y academia, el alcance de la diplomacia hubiera sido mayor. Uno puede señalar que de todos modos el que se haya realizado independientemente de las características es bueno. Mientras no exista continuidad con los acercamientos y se impulse un mayor intercambio con una clara coordinación y la SRE sea el centro de la elaboración e implementación de políticas, seguiremos con políticas de corto plazo y manejadas por el presidente o diferentes secretarios de dependencias de corte tecnocrático.

Por lo tanto, es necesario que la SRE desempeñe un papel central, con un adecuado presupuesto que le permita contar con el personal suficiente y en condiciones favorables para realizar sus labores. La desaparición de ProMéxico tiene grave consecuencias para la promoción de México en el exterior y para la propia Secretaría de Relaciones Exteriores, pues si a lo anterior sumamos la falta de personal tanto especializado como no especializado en las embajadas, las tareas que conlleva el encauzar el intercambio de productos e inversiones, se tendría que replantear el papel de una instancia encargada exclusivamente de la promoción y en sincronía con las acciones realizadas por la SRE y sus representantes diplomáticos. No se puede exigir a una Secretaría con bajo presupuesto, tener personal con conocimiento especializado y focalizado en economía y comercio, generar información de inteligencia económica y financiera sobre los mercados objetivos, además de las labores de seguimiento en los procesos de apertura de mercados tanto a nivel externo como interno.

\section{Referencias}

ANDERSON, Bárbara (2019): "Cinépolis inicia plan de expansión en países árabes e Indonesia", Milenio, 1 julio, disponible https://www.milenio.com/negocios/cinepolis-inicia-plan-expansionpaises-arabes-indonesia [consulta: 10 de diciembre 2019].

BIBIÁN, Cinthia (2014): "Helvex abre la llave de Medio Oriente", Expansión, 2 de agosto, disponible http://obrasweb.mx/soluciones/2014/08/04/helvex-abre-la-llave-de-medio-oriente [consulta: 21 de marzo 2019].

BRUN, Élodie y GARZA, Humberto (2019): “La Política Exterior de México entre 1970 y 1982: la búsqueda de nuevas estrategias", en BRUN, Élodie y GARZA, Humberto: El tercermundismo y la diplomacia del petróleo. La política exterior de Luis Echeverría y José López Portillo, 1970-1982, Antología de Política y Relaciones Internacionales de Foro Internacional, vol. 4, México, El Colegio de México. pp. 11-40.

Comunicado conjunto del Gobierno de Qatar y México, noviembre 24, 2015, disponible https://www.gob.mx/cms/uploads/attachment/file/29940/comunicado conjunto mexico qatar. pdf [consulta: 25 de marzo 2019].

DE LA MORA, Luz María (2019): “La política comercial de México durante el gobierno del presidente Enrique Peña Nieto (2012-2018)", Foro Internacional, LIX, 3-4. pp. 959-988. DOI: https://doi.org/10.24201/fi.v59i3-4.2648

ECONOMIST, Intelligence Unit (2016): Bridging the Gulf: Latam-GCC trade and investment, disponible en https://eiuperspectives.economist.com/sites/default/files/EIU- 
Dubai\%20Chamber\%20Bridging\%20the\%20Gulf\%2027th\%200ctober\%202016.pdf [ consulta: 8 de diciembre 2019].

El Correo del Golfo (2017): "El Golfo, objetivo estratégico para México", El Correo del Golfo, 1-31 de marzo, disponible http://elcorreo.ae/sites/default/files/archivos/el correo del golfo n 35 marzo 2017.pdf

[consulta: 25 marzo 2019].

El Economista (2018): "Qatar Petroleum firmó acuerdo para adquirir 35\% de la plataforma petrolífera Área 1 en México", El Economista, 17 de diciembre, disponible https://www.eleconomista.com.mx/empresas/Qatar-Petroleum-firmo-acuerdo-para-adquirir-35de-la-plataforma-petrolifera-Area-1-en-Mexico-201 [consulta: 25 de marzo 2019].

El Economista (2016): "México y Arabia Saudita firman 11 acuerdos", El Economista, 17 de enero, disponible https://www.eleconomista.com.mx/politica/Mexico-y-Arabia-Saudita-firman-11acuerdos-20160117-0095.html [consulta: 20 de marzo 2019].

El Universal (2013): "Abren puertas del Medio Oriente para Carlos Slim", El Universal, 7 de mayo, disponible en: http://m.redpolitica.mx/nacion/abren-puertas-del-medio-oriente-para-carlos-slim [consulta: 25 de marzo 2019].

El Universal (2016a): “México destinará 3mdd en ayuda a víctimas sirias”, El Universal, 4 de febrero, disponible universal.com.mx/articulo/nacion/sociedad/2016/02/4/mexico-destinara-3mdd-enayuda-victimas-sirias [consulta: 19 de marzo 2019].

El Universal (2016b): “Acuerdos con Qatar potenciarán la relación bilateral: EPN”, El Universal, 21 de enero, disponible

http://www.eluniversal.com.mx/articulo/nacion/politica/2016/01/21/acuerdos-con-qatarpotenciaran-relacion-bilateral-epn [consulta: 25 de marzo 2019].

El País (2015): “El fondo de Kuwait invierte en una filial de Gas Natural 500 millones", El País, 3 de marzo, disponible https://elpais.com/economia/2015/03/30/actualidad/1427726990 229312.html[consulta: 25 de marzo 2019].

ESTEVEZ, Dolia (2013): “Is Mexican billonaire Carlos Slim out to conquer Saudi Arabia?”, Forbes, 22 de abril, disponible https://www.forbes.com/sites/doliaestevez/2013/04/22/is-mexicanbillionaire-carlos-slim-out-to-conquer-saudi-arabia/\#6ea7fad91aad [consulta: 25 de marzo 2019].

FRANZONI, Marcela (2017): “La Política Exterior de México en el gobierno de Peña Nieto: retos locales e internacionales", Contextualizaciones Latinoamericanas, vol. 9, núm. 17. pp. 1-9. DOI: https://doi.org/10.32870/cl.v0i17.7033

GALINDO, Alejandra (2018): “Mexico and Brazil's Approach Towards the GCC Mexico and Brazil's Approach Towards the GCC Mexico and Brazil's Approach Towards the GCC", Research Paper, Arab Center for Research and Policy Studies, Doha Institute, disponible en https://www.dohainstitute.org/en/ResearchAndStudies/Pages/Mexico-and-Brazil\%E2\%80\%99s-

Approach-Towards-the-GCC-Countries-An-Assessment-of-Economic-Diplomacy-.aspx [consulta: 25 de marzo 2019].

GALINDO, Alejandra (2012): “Mexico's Elusive Foreign Policy towards the Middle East: between Indifference and Engagement", Contemporary Arab Affairs, vol.4, núm. 2, pp.341-359. DOI: https://doi.org/10.1080/17550912.2011.593959

GARCÍA, Ariadna (2002): "Prevé SRE cerrar más embajadas por recorte", El Universal, 18 de diciembre, disponible https://archivo.eluniversal.com.mx/nacion/91796.html [consulta: 19 de marzo 2020]. 
GUSI, (2017): "Gusi Prime Empresa en Exportar Carne a Qatar", Gusi, S/F, disponible http://www.grupogusi.com.mx/noticias/primer empresa mexicana en exportar carne a qatar. php [consulta: 25 de marzo 2019].

HABBOUSH, Mahmoud (2018): "Esta empresa árabe generará energía solar en San Luis Potosi”, EI Financiero, 16 de enero, disponible http://www.elfinanciero.com.mx/empresas/esta-empresaarabe-generara-energia-solar-en-san-luis-potosi [consulta: 26 de marzo 2019].

Instituto Halal (2017): "El Instituto Halal cuenta con 50 empresas certificadas en México", Actualidad, 9 de diciembre, disponible https://www.institutohalal.com/el-instituto-halal-cuentacon-50-empresas-certificadas-en-mexico/ [consulta: 26 de marzo 2019].

Kuwait Times (2016): "Kuwait, Mexico sign agreements, memos - Amir, Mexican President exchange medals", Kuwait Times, 20 de enero, disponible http://news.kuwaittimes.net/website/kuwait-mexico-sign-agreements-memos/ [consulta: 19 de marzo 2019].

MORALES, Roberto (2016): “Apuestan a relación de largo plazo con Medio Oriente”, El Economista, 27 de enero, disponible en: https://www.eleconomista.com.mx/empresas/Apuestan-a-relacion-delargo-plazo-con-Medio-Oriente-20160127-0069.html [consulta: 19 de marzo 2019].

MVS Noticias (2016). “Empresarios acompañan a Peña Nieto al Medio Oriente para participar en reuniones comerciales", MVS Noticias, 18 de enero, disponible https://mvsnoticias.com/noticias/nacionales/empresarios-acompanan-pena-nieto-al-mediooriente-para-participar-en-reuniones-comerciales-394/ [consulta: 8 de diciembre 2020].

Oficina enlace en Palestina, disponible https://oficinaenlace.sre.gob.mx/palestina/index.php/oficina-de-representacion [consulta: 8 de diciembre 2020]

PELLICER, Olga (2014). La política exterior de México bajo un nuevo presidente. Anuario Cidob, disponible

en

https://www.cidob.org/articulos/anuario internacional cidob/2014/la politica exterior de mexi co bajo un nuevo presidente [consulta: 20 de marzo].

PEMEX (2016): "Pemex subscribes memorandums of understanding with three arab oil companies", comunicado de prensa, 19 de enero, disponible http://www.pemex.com/en/press room/press releases/Paginas/2016-006-national.aspx [consulta:19 de marzo 2019].

PÉREZ, Marta (2016): "El secretario de Agricultura de México impulsa la exportación de alimentos de su país al Golfo", Correo del Golfo, 16 de mayo, disponible http://elcorreo.ae/economia/girasecretario-agricultura-mexico-por-golfo-para-impulsar-exportacion-alimentos-region [consulta: 26 de marzo 2019].

PR News Wire (2016): “Grupo Vidanta se asocia con Hakkasan Group para traer a México innovadoras experiencias en entretenimiento y restaurantes con una inversión de $150 \mathrm{Mdd}$ ", $P R$ News Wire, 20 de abril, disponible en: https://www.prnewswire.com/news-releases/grupovidanta-se-asocia-con-hakkasan-group-para-traer-a-mexico-innovadoras-experiencias-enentretenimiento-y-restaurante [consulta:19 de marzo 2019]. 
Presidencia de la República (2013): Plan Nacional de Desarrollo 2013-2018, México, Diario Oficial de la Federación, 20 de mayo 2007, disponible http://pnd.gob.mx/wpcontent/uploads/2013/05/PND.pdf [consulta: 18 de marzo 2019].

Presidencia de la República (2007): Plan Nacional de Desarrollo 2006-2012, Diario Oficial de la Federación, 31 de mayo 2007, disponible en: http://pnd.calderon.presidencia.gob.mx/pdf/PND 2007-2012.pdf [consulta: 18 de marzo 2019].

RESÉNDIZ, F. (2016): “México y Emiratos firman Trece Acuerdos", El Universal, 17 de enero, disponible http://www.eluniversal.com.mx/articulo/nacion/politica/2016/01/19/mexico-yemiratos-arabes-firman-13-acuerdos-de-cooperacion\#imagen-1 [consulta: 25 de marzo 2019].

RODRÍGUEZ, Karla y NAVA, Diana (2017): "Fondo con sede en Dubái tiene en la cartera 1,500 mdd para México y AL", El Financiero, 30 de marzo, disponible http://www.elfinanciero.com.mx/empresas/abraaj-group-cuenta-con-mil-500-mdd-para-fondearempresas-en-latam [consulta: 25 de marzo 2019].

SADER, (2017): "Avanza diversificación de mercados hacia el mundo árabe en la México Alimentaria 2017", Sader, comunicado de prensa, 13 de diciembre, disponible https://www.gob.mx/sader/zacatecas/articulos/avanza-diversificacion-de-mercados-hacia-elmundo-arabe-en-la-mexico-alimentaria-2017-142568?idiom=es [consulta: 26 de marzo 2019].

SAGARPA (2016): Comunicado de Prensa, 19 de septiembre, disponible en https://www.gob.mx/sader/prensa/mexico-se-consolida-como-proveedor-de-alimentos-decalidad-para-el-mundo-jose-calzada-rovirosa?idiom=es [consulta: 26 de marzo 2019].

Secretaría de Economía (2016): “El Gobierno de la República presenta Estrategia Nacional para la Promoción de las Exportaciones Mexicanas hacia el Mercado Halal", comunicado de prensa, 14 de enero, disponible en: https://www.gob.mx/se/prensa/el-gobierno-de-la-republica-presentaestrategia-nacional-para-la-promocion-de-las-exportaciones-mexicanas-hacia-el-mercado-halal

[consulta 25 de marzo 2019].

UNCTAD (Conferencia de las Naciones Unidas para el Comercio y Desarrollo), Datos estadísticos, disponible_https://unctad.org/statistics.

VARELA, Hilda y SÁNCHEZ, Indira (2007): África y Medio Oriente, vol. 7, Historia de las Relaciones Internacionales de México 1820-2010, México, Secretaría de Relaciones Exteriores.

WEBER, J. (2018): “Mexico raises close to $\$ 100 \mathrm{bn}$ in oil sector investment", Financial Times, 31 de enero, disponible https://www.ft.com/content/993f5718-06c7-11e8-9650-9c0ad2d7c5b5 [consulta: 27 de marzo 2019].

WOERTZ, Eckart (2015). Oil for Food, Oxford, Oxford University Press.

WOOD, Duncan ed. (2018): La nueva reforma energética de México, Washington: Mexico institute, Woodrow Wilson Center, disponible https://www.wilsoncenter.org/sites/default/files/media/documents/publication/la nueva reform a energetica de mexico.pdf [consulta: 8 de diciembre 2019].

\section{Entrevistas}

AMPUDIA, Luis y ESTEVES, Claudia: Proméxico, Ciudad de México, entrevista personal con Vivian Calles, 18 de marzo 2015.

BARBOSA, R y TORRES, Luis: Dirección de África y Medio Oriente, Ciudad de México, Entrevista Personal con Vivian Calles, 19 de marzo 2015.

CEPEDA, Juan: Proméxico. Doha, Qatar, Entrevista Personal 24 de febrero 2016. 
GALÁN, Francisco: Encargado de Negocios, Embajada de Emiratos Árabes en México, Ciudad de México, entrevista personal con Vivian Calles, 18 de marzo 2015. 